\title{
Indicated factors of physical development, physical readiness, functional condition and efficiency of female students in the process of adaptation to training
}

\author{
Avdeeva M.S. ${ }^{1 \mathrm{ABCD}}$, Tulyakova O.V. ${ }^{2 \mathrm{ABCD}}$ \\ ${ }^{1}$ Department of Physical Education, Vyatka State University, Russia \\ ${ }^{2}$ Department of Students'Research Work, Vyatka State University, Russia
}

Authors' Contribution:

A - Study design; B - Data collection; C - Statistical analysis; D - Manuscript Preparation; E - Funds Collection.

\begin{abstract}
Purpose: $\quad$ to determine indicated factors of physical development, physical readiness, functional condition and efficiency of

Material: $\quad$ it was examined female students at the beginning of the first and second year of training ( $n=342$, age 18-20 years). The investigation was conducted on 10 indicators of physical development, 9 indicators of physical preparedness and 13 indicators of functional status and performance.

Results: It is established that during the first year of study takes place changes in the factors of the physical development of students, such as: increase of body weight, mass-growth index, muscular strength of the right hand. From the factors of physical readiness: increase the time of the visibility on the crossbar and the number of push-ups from the floor; decreases the length of the jump from the place. From the factors of the functional state: the frequency of breathing and the Genci test increase; decrease the coefficient of circulatory efficiency, endurance factor and systolic blood pressure.

Conclusions: Indicated factors of female students' adaptation to learning is to be considered the strength of the hand (factor of physical development), long jump from the place (factor of physical preparedness), the Genci test (factor of the functional state), the coefficient of circulation efficiency and the endurance factor.

Keywords: $\quad$ physical development, physical readiness, functional state, adaptation, training, working capacity.
\end{abstract}

\section{Introduction}

There is a problem of determining indicated factors of physical development and the functional state of students. At the initial stage of training, the health of young people is deteriorating $[1,2]$. This is due to a decrease in motor activity [3], a decrease in motivation to exercise, [4], excessive interest in the Internet and gadgets [5], unhealthy eating behavior [6, 7]. It is also associated with climatic [8], geographical [9] and environmental conditions $[10,11]$, adaptation to a new way of life [12, 13], the appearance of bad habits [14], deterioration in the socio-moral qualities of the person $[15,16]$. Thus, the functional state of the circulatory system is estimated as "a tension of adaptation mechanisms" among $8 \%$ of students [17]. This is due to the period of adaptation to the new conditions. Long-term preservation of such conditions leads to depletion of the body's functional reserves, contributes to the development of diseases. The authors consider the process of studying at the university as a factor that negatively affects the health of young people [18].

In other studies [19] it is noted that 217 medical students develop chronic emotional stress during 1-3 training courses. The severity of this stress depends on the individual psychophysiological status of students. $60 \%$ of the students initially did not have sufficient adaptive capacity. This led to psychological problems and disorders of the autonomic nervous system. The authors show [20] that the processes of students' adaptation to learning can be assessed by the nature of the shifts in the parameters of heart rate variability. Positive trends were established in the first three courses. At the senior courses the tension (c) Avdeeva M.S., Tulyakova O.V., 2018 doi:10.15561/20755279.2018.0101 of mechanisms of regulation of a warm rhythm amplifies. Student survey [21] (1 course, Amur State University, Russia, 2000-2014) made it possible to reveal a number of statistically significant changes during the training: the speed decreased by $8,16 \%$; total endurance - by $9,75 \%$; strength muscle endurance - by $30 \%$; speed-strength (dynamic force of the legs) - by 5,28\%; agility - by $9,45 \%$; The index of flexibility - by $43,6 \%$.

Indicators of students' health can be improved through sports. It is important to optimize physical activity [22, 23], to form a positive attitude toward one's health [24], to take into account the didactic patterns of training [25], to select adequate tests [26], pedagogical control of motor activity [27]. In classes on the physical education of students, it is necessary to take into account the following: the initial parameters of health level [28]; parameters of the psychological state [29]; morphofunctional health parameters [30]; individual health parameters [31]; criteria for restoring health [32]; new technologies in physical education [33, 34]; standards of physical education [35, 36]; models of motor development and competence [37, 38]; the effect of physical training on academic performance [39]; features of sports pedagogy [40].

A topical issue remains the question of determining the criteria, procedures, methods for assessing indicated factors of students' adaptation to learning. Many of the indicators are ununified. Their combination is different in various studies. This makes it difficult to verify the results. The informativeness of the used factors is not studied in full and become the subject of discussion in the scientific community. Therefore, the question arose about the formation of a complex of indicated factors. 
Indicated factors are important for the analysis of ontogenetic development and evaluation of the functional state of the leading systems of the body. They can be used to assess the adequacy of motor regimes [41, 42].

In the literature, it is proposed to use as indicator indices the following: long jump from the place [43], breath delay on the exhalation (the Genci test) and the Ruffier index [44], heart rate variability indices [20], maximum oxygen consumption [45], MartineKushelevsky test [41], the results of hand dynamometry $[46,47]$. The literature data on the informativeness of the mass-growth index are contradictory [48]. In general, the presented data are fragmented, there is no systematic approach to determining indicated factor.

Hypothesis: one assumes that in order to successfully solve the issue it is necessary to identify informative indicator indices of adaptation to learning.

The purpose of the study is to determine the indicated factors of physical development, physical readiness, functional condition and efficiency of female students in the process of adaptation to learning.

\section{Material and methods}

Participants. The study involved students $(n=342)$ of the first year of study (aged 18,35 $\pm 0,04$ years) and the second year (aged 20,33 $\pm 0,92$ years) of study. The research was conducted during the first and third semesters (September and October month). During the research no one complained of health problems. All the students gave voluntary consent to participate in the research.

Organization of the study. It was examined 32 indicators: 10 on physical development, 9 on physical fitness and 13 on functional condition and performance.

To measure physical development, the body length $(\mathrm{cm})$, body weight $(\mathrm{kg})$ and circumference of the chest (CC, cm) were measured [49].

The flexion muscle strength $(\mathrm{kg})$ of the right and left hand was measured using the hand dynamometry method [50]. Then the power index was calculated: the percentage of muscle strength to body weight.

To assess the status of cardiovascular system (CVS) in rest conditions it is evaluated heart rate (HR), systolic blood pressure (SBP) and diastolic blood pressure (DBP) (mmHg) [51].

To assess the state of the respiratory system it was measured the vital capacity of the lungs (VCL, l), it was performed the Stange test and the Genci test. VCL was measured with a portable spirometer [52] and calculated the vital index (VI): the ratio of VCL to body weight (ml / kg). The Stange test (c) was performed as follows: the student in standing position breathes in; then the student makes a deep exhalation; then the student takes a breath that is $80-90 \%$ of the maximum; then the student holds his breath. There is a time delay in breathing. In the Genci test (c) after a normal exhalation, the student holds his breath as long as possible [53].

Physical efficiency was assessed by the maximum oxygen consumption (MOC, $\mathrm{ml} / \mathrm{min}$ ). Calculation of MOC was carried out according to the work power and the heart rate recorded during the step test (climbing the bench at a height of 0,35 $\mathrm{m}$ for 4 minutes at a frequency of 20 cycles per minute). The working power $\mathrm{N}$, in $\mathrm{kg} \mathrm{m} /$ min, was found from the formula:

$$
\mathrm{N}=1,2 \times \mathrm{P} \times \mathrm{h} \times \mathrm{n},
$$

where $\mathrm{P}$ - is the body weight of the subject (kg); h bench height (m); $\mathrm{n}$ - is the number of cycles (min); 1,2 - coefficient of ascent and descent.

The MOC was calculated using the Dobeln formula:

$$
\mathrm{MOC}=\mathrm{A} \times[\mathrm{N} /(\mathrm{H}-\mathrm{h})]^{-1 / 2} \times \mathrm{K},
$$

where $\mathrm{A}$ - is the empirical correction to the formula, depending on age and gender; $\mathrm{N}$ - power of work, in kg/ min; $\mathrm{H}$ - heart rate (bpm) at a given work power; $\mathrm{h}$ - agesexual correction to the pulse, $\mathrm{K}$ - age coefficient [53].

The Kredo index was calculated by the formula:

$$
\mathrm{KI}=(1-\mathrm{D} / \mathrm{P}) \times 100,
$$

where $\mathrm{D}$ - is the diastolic pressure ( $\mathrm{mmHg}$ ), $\mathrm{P}$ - is the pulse (heart rate), bpm [53].

The coefficient of efficiency of blood circulation (CEBC) was calculated by the formula:

$$
\mathrm{CEBC}=(\mathrm{SBP}-\mathrm{DBP}) \cdot \mathrm{HR},
$$

where SBP - systolic blood pressure (mmHg), DBP diastolic blood pressure (mmHg), HR - heart rate (bpm) [53].

The coefficient of endurance (CE) was determined by the Kvass formula:

$$
\mathrm{CE}=(10 \cdot \mathrm{HR}): \mathrm{PP},
$$

where HR is the heart rate (bpm), PP is the pulse pressure (mmHg). The PP was calculated as the difference between SBP and DBP [53].

Adaptation to learning was assessed by the value of the adaptation potential (AP):

$$
\begin{gathered}
\mathrm{AP}=0,011 \cdot \mathrm{HR}+0,014 \cdot \mathrm{SBP}+0,008 \cdot \mathrm{DBP}+0,09 \cdot \\
\mathrm{BM}-0,009 \cdot \mathrm{W}+0,014 \cdot \mathrm{A}-0,27,
\end{gathered}
$$

where BM - body mass $(\mathrm{kg}), \mathrm{W}$ - weight $(\mathrm{cm}), \mathrm{A}-$ age in years [53].

To determine physical fitness, the level of development of the basic motor qualities was assessed in accordance with the "Model program of the discipline "Physical Culture" [54]. According to this program, the girls practiced physical culture 2 times a week for 2 hours. The annual load of 144 hours was evenly distributed over semesters. The program included such sections as: athletics (42 hours), volleyball (28 hours), athletic gymnastics (42 hours), swimming (28 hours), tests (4 hours). Classes were conducted according to a typical structure: the introductory part (15-20 min), the main part 
(35-45 $\mathrm{min})$, the final part (19-15 $\mathrm{min})$. The introductory part consisted of a set of general development exercises. The main part consisted of the exercises of the relevant sections (see below). The final part consisted of a set of breathing exercises and exercises that developed flexibility. Here is an example of the content of the main part of the classes:

1) in the track and field athletics classes studied the technique of improving run, special exercises of the runner, running technique for long and short distances, technique of jumping in length from the place. Also prepared for the implementation of control standards for athletics (running $30 \mathrm{~m}, 100 \mathrm{~m}, 2000 \mathrm{~m}$ ).

2) in the volleyball classes studied the basic rules of the game, overarm reception, attack blow, blocking the ball, group and team interactions.

3) in the swimming lessons, we studied feeding exercises, gliding on the chest and back, movements of the hands and feet in the rabbit on the back and chest.

4) athletic gymnastics classes developed strength qualities, power endurance. In the lesson, exercises with weights and exercises were used. Also prepared for the implementation of control standards for general physical training (flexion and extension of the arms in the supine position, the torso of the trunk from the supine position on the back, hanging on the crossbar).

During the training, group and individual game simulation methods were used.

At the end of each semester, the students passed the following tests: (in the conditions of sports hall and stadium): running at 30 and $100 \mathrm{~m}$ (speed); a long jump from the place (speed force); inclination from the standing position on the bench (flexibility); flexion and extension of the arms in the supine position; hanging on the crossbar; slopes from the supine position on the back (power endurance); running at $1000 \mathrm{~m}$; running for 2000 m (total endurance).

Statistical analysis. The results of the investigation were processed in the Microsoft Excel Licensed Software
Package. The quantitative data were verified for the normal distribution in several ways (an estimate of the symmetry of the sample by the histogram and the Kolmogorov-Smirnov method). Further, the indicators of descriptive statistics were calculated: the arithmetic mean $(\mathrm{M})$, the standard deviation $(\sigma)$, and the error of the mean value (m).

In the text and tables are presented as $\mathrm{M} \pm \mathrm{m}$. The differences were estimated by the Student's criterion $(\mathrm{t})$ for independent samples and the chi-square test: they were considered reliable at $\mathrm{p}<0.05$ (in the text is indicated as “*”).

\section{Results}

It is established that the data obeys the law of normal distribution, according to our study. This is confirmed by the estimation of the symmetry of the sample in the histogram. Figures 1-3 give examples of histograms for the parameters of physical development (body weight), physical readiness (long jump from the place) and functional state (the Genci test).

The study found statistically significant differences in 11 indicators (out of 32 indicators) (Table 1-3). From the indicators of physical development is increased: body weight, mass-growth index, muscular strength of the right hand. According to the mass-growth index, 12,83\% of students had a body weight deficit, $16,37 \%$ had excess body weight.

From the indicators of physical preparedness, the time spent on the hanging on the crossbar and the number of push-ups from the floor increased. The length of the jump from the place decreased.

From the indicators of the functional state and working capacity, the frequency of breathing and the Genci test increased. The coefficient of efficiency of blood circulation, endurance factor, systolic blood pressure decreased.

The study established a number of statistically

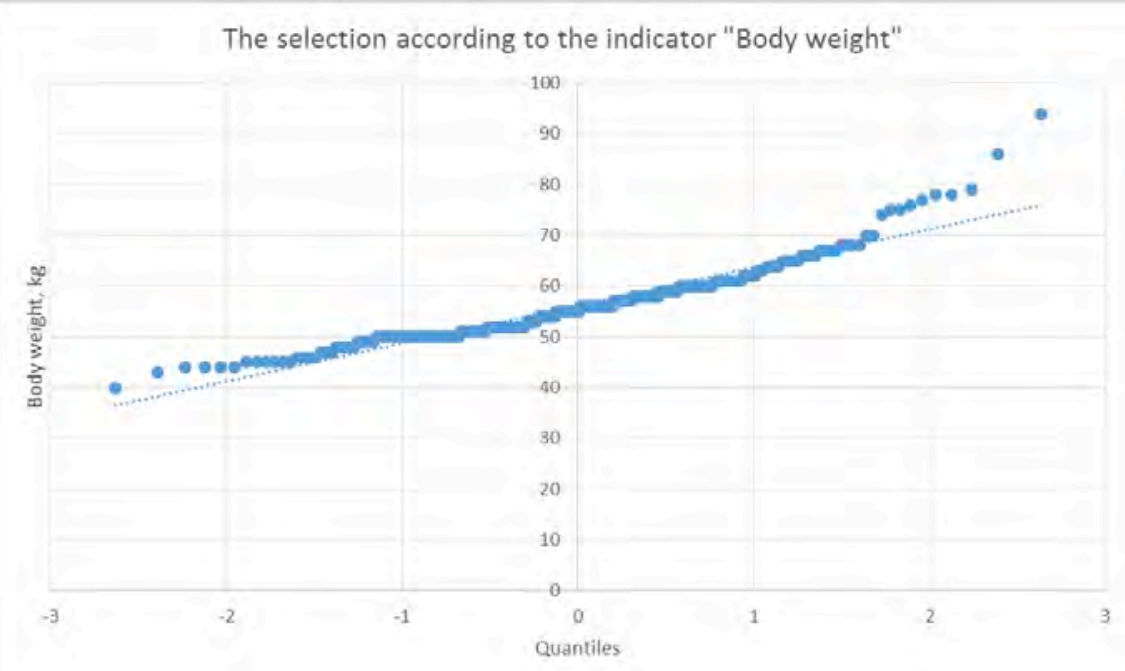

Fig. 1. Evaluation of the symmetry of the sample according to the histogram for the indicator "Body mass" 


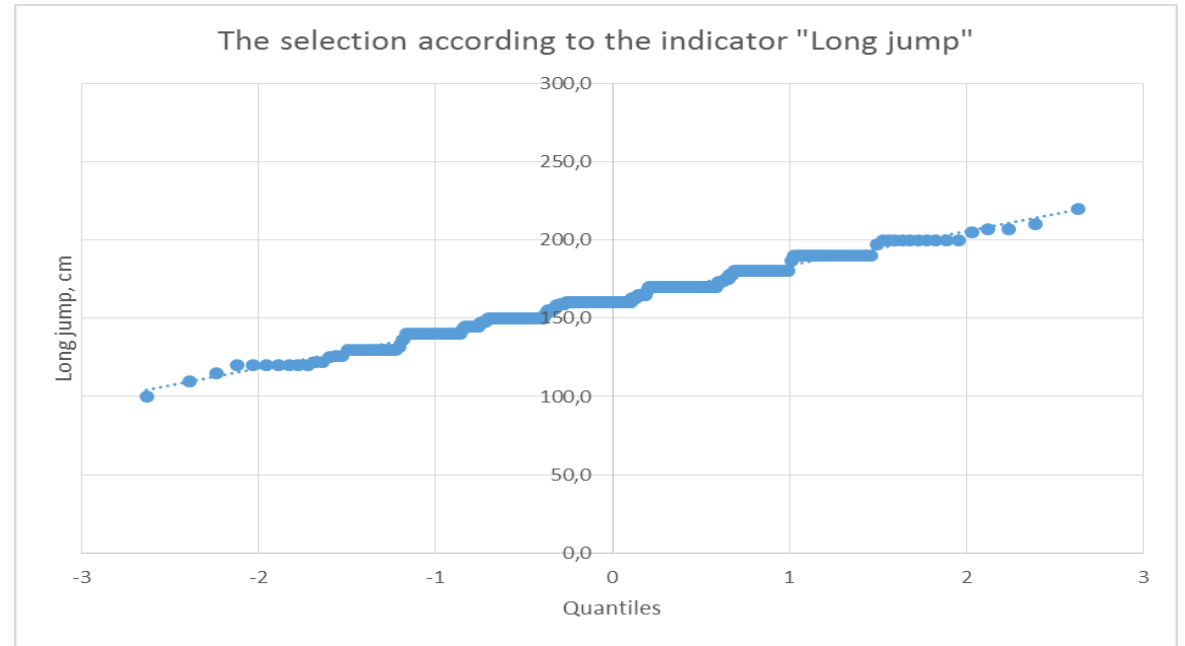

Fig. 2. Evaluation of the symmetry of the sample according to the histogram for the "Long jump"

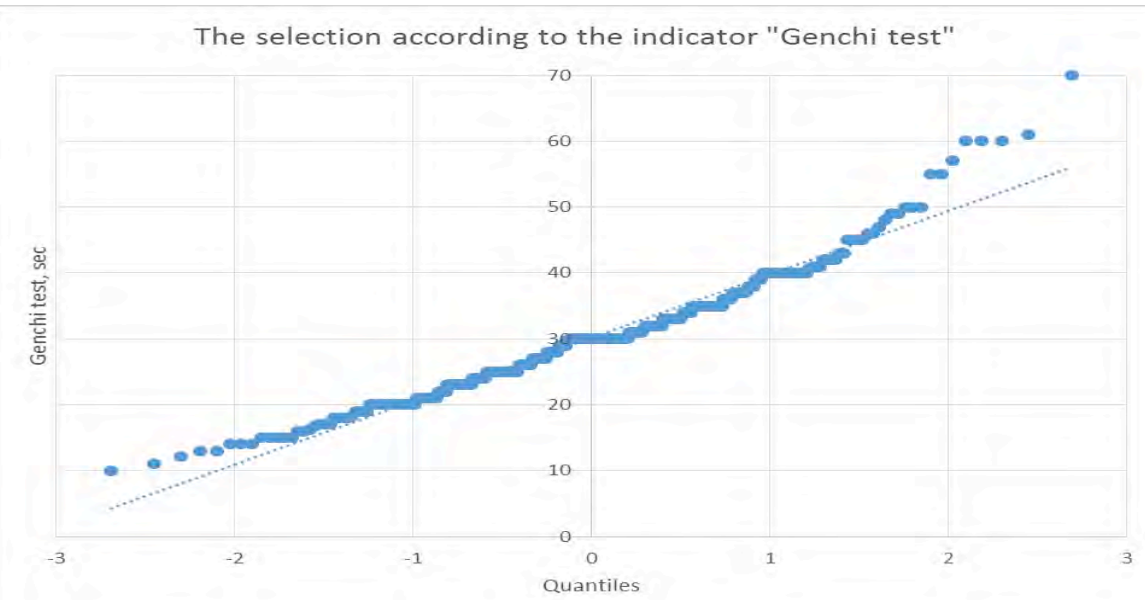

Fig. 3. Evaluation of the symmetry of the sample according to the histogram for the indicator of the "Genci Test"

Table 1. Physical development of female students

\begin{tabular}{llllllll}
\hline \multirow{2}{*}{ Parameters } & \multicolumn{2}{l}{ Group 1 } & \multicolumn{3}{l}{ Group 2 } \\
& n & M & m & n & M & m \\
\hline Body length, $\mathrm{cm}$ & 235 & 164,25 & 0.36 & 270 & 165,28 & 0,53 \\
Body weight, kg & 236 & 56,19 & 0.50 & 260 & $58,57^{*}$ & 0,99 \\
Mass-growth index & 226 & 341,32 & 3,21 & 258 & $351,36^{*}$ & 3,28 \\
Muscular strength of the right hand, kg & 334 & 22,61 & 0,26 & 241 & $23,85^{*}$ & 0,98 \\
Muscular strength of the left hand, kg & 333 & 20,64 & 0,25 & 241 & 22,23 & 1,00 \\
Power index & 218 & 40,74 & 0,63 & 235 & 40,65 & 1,17 \\
Circumference of chest, in the rest, cm & 342 & 85,04 & 0,30 & 269 & 85,99 & 0,78 \\
Circumference of chest, breath, cm & 342 & 89,60 & 0,30 & 269 & 90,61 & 0,76 \\
Circumference of chest, exhalation, cm & 342 & 83,24 & 0,29 & 269 & 83,61 & 0,79 \\
Chest excursion & 342 & 6,35 & 0,12 & 269 & 7,99 & 0,99 \\
\hline
\end{tabular}

Note: * - the differences are reliable, $p>0,05$ 
Table 2. Physical preparedness of female students

\begin{tabular}{lllllll}
\hline \multirow{2}{*}{ Parameters } & \multicolumn{2}{l}{ Group 1 } & \multicolumn{3}{c}{ Group 2 } \\
& $\mathbf{n}$ & $\mathbf{M}$ & $\mathbf{m}$ & $\mathbf{n}$ & $\mathbf{M}$ & $\mathbf{m}$ \\
\hline $1000 \mathrm{~m}, \mathrm{~min}$ & 199 & 5,07 & 0,06 & 179 & 6,11 & 0,97 \\
$2000 \mathrm{~m}, \mathrm{~min}$ & 34 & 11,94 & 0,28 & 29 & 11,73 & 0,28 \\
$100 \mathrm{~m}, \mathrm{sec}$ & 23 & 18,29 & 0,41 & 20 & 18,25 & 0,41 \\
$30 \mathrm{~m}, \mathrm{sec}$ & 213 & 5,43 & 0,04 & 200 & 6,38 & 0,97 \\
Broad jump from the place, m & 237 & 164,10 & 1,31 & 241 & $159,66^{*}$ & 1,30 \\
Bending and extension of arms in support, times & 249 & 9,91 & 0,46 & 220 & $12,58^{*}$ & 1,09 \\
Body sit-up for 30 sec., times & 233 & 22,77 & 0,71 & 242 & 23,06 & 0,95 \\
Hanging on a crossbar, sec & 241 & 8,66 & 0,64 & 200 & $11,40 *$ & 1,16 \\
Inclination forward from standing position, $\mathrm{cm}$ & 236 & 12,43 & 0,62 & 199 & 13,00 \\
\hline
\end{tabular}

Note: $*$ - the differences are reliable, $p>0,05$

Table 3. Functional state and efficiency of female students

\begin{tabular}{lllllll}
\hline \multirow{2}{*}{ Parameters } & \multicolumn{2}{l}{ Группа $\mathbf{1}$} & \multicolumn{3}{c}{ Группа 2 } \\
& $\mathbf{n}$ & $\mathbf{M}$ & $\mathbf{m}$ & $\mathbf{n}$ & $\mathbf{M}$ & $\mathbf{m}$ \\
\hline Vital capacity of lungs, ml & 333 & 2794,74 & 28,16 & 258 & 2872,81 & 42,74 \\
Vital index, ml/kg & 229 & 49,43 & 0,79 & 246 & 51,51 & 1,14 \\
respiration rate, for 1 min & 333 & 16,45 & 0,21 & 261 & $19,06^{*}$ & 1,27 \\
The Stange test, c & 283 & 47,81 & 0,81 & 255 & 48,26 & 1,24 \\
The Genci test, c & 279 & 30,18 & 0,58 & 255 & $32,84^{*}$ & 1,10 \\
Maximum of oxygen consumption, ml/min & 146 & 9,74 & 0,24 & 256 & 10,82 & 0,99 \\
Kredo index & 327 & 17,16 & 0,92 & 228 & 16,31 & 1,53 \\
The coefficient of efficiency of blood circulation & 327 & 3782,07 & 58,16 & 226 & $3460,18 *$ & 68,46 \\
The coefficient of endurance & 327 & 18,80 & 0,33 & 215 & $15,30^{*}$ & 0,97 \\
The adaptation potential & 327 & 2,24 & 0,03 & 218 & 2,99 & 0,99 \\
Heart rate, bpm & 336 & 81,89 & 0,64 & 264 & 81,22 & 1,02 \\
SBP - systolic blood pressure (mmHg) & 330 & 113,86 & 0,71 & 228 & $111,21 *$ & 0,95 \\
DBP - diastolic blood pressure (mmHg) & 330 & 66,78 & 0,52 & 228 & 68,42 & 0,95 \\
\hline
\end{tabular}

Note: $*$ - the differences are reliable, $p>0,05$

significant differences in physical development, physical fitness, functional status of female students. It is increased the body weight, mass-growth index, muscular strength of the right hand, the time of hanging on the crossbar, the number of push-ups from the floor; breathing rate. Decreased the length of the jump from the place, the Genci test, the coefficient of efficiency of circulation, endurance factor, systolic blood pressure.

\section{Discussion}

The results of our study correspond to the physical development of school leavers [55] and female students [56] in Kirov (Russia), students from Nizhny Novgorod (Russia) [57], Cherepovets (Russia) [58] and Kazan (Russia) [59].

Physical development. The data obtained by us on the increase in body weight in first-year students confirm the literature data. According to [60], the girls added about $1 \mathrm{~kg}$ of weight during the first year of schooling at the university. The authors consider the first semester to be a critical period in the weight set [60]. They attribute this to significant changes in life [12] and unhealthy eating behavior [61]. In another study of Belgian female students, weight and body mass index for the first 1,5 years at the university have not changed [62]. Thus, the literature data on the informativeness of the mass-growth index are contradictory [48]. The data obtained on the increase in the muscular strength of the right hand (increased by 1,85 $\mathrm{kg}$ ) are consistent with the literature data [62].

Physical fitness. The data obtained by us agree with the literature data [58]. They testify to ambiguous dynamics of speed-strength and strength qualities of female students during the first year of study. In particular, about the improvement of power qualities (flexion and extension of the arms in the support lying hanging on the crossbar) and deterioration of the speed-strength qualities (long jump from the place). Other authors [63] is recognized jump in length from the place as the most informative indicator for the evaluation of muscle strength. In our opinion, the decrease in the "long jump" may be due to an increase in body weight and a general decrease in motor activity. According to [58], this is due to the selective activity of certain muscle groups and their ability to maximal power and speed. This ability, in the 17-18 
years, is predominantly manifested by the muscles of the lower extremities involved in performing the jumping exercises (speed strength). In 20 years, this ability is mainly manifested by the muscles of the abdomen and back (power endurance). For the first time we have shown the increase in the process of adaptation to learning such indicators as: time of the hanging on the crossbar; amount of push-ups from the floor.

Functional state and efficiency. The data obtained by us on the state of the respiratory system testify to the multidirectional processes in the body of female students in adapting to training. An increase in the frequency of respiration at rest indicates disadaptation processes. Increased respiratory retention on exhalation (the Genci test) indicates adaptive processes. The Genci test is considered to be an informative indicator of the health of students [18]. There is a decrease in indicators: CEBC, systolic blood pressure; coefficient of endurance. In this case, the CEBC and the endurance coefficient tend to the physiological norm. We believe that supporting activities in physical culture played an important role in this. For the first time we showed a decrease in the process of adaptation to learning indicators: CEBC, systolic blood pressure; coefficient of endurance.

In our opinion, the indicator indices for the adaptation of female students to learning are characteristics with statistically significant differences. We suggest using those that are confirmed by consistent information in the literature.
We include such indicators: the results of hand dynamometry (an indicator of physical development), a long jump from the place (an indicator of physical readiness), the Genci test (an indicator of the functional state). We also propose to use CEBC and endurance factor as indicators of functional status. This choice is due to the fact that in the process of adaptation, their values tend to a physiological norm.

We do not agree with a number of authors [19] who consider the learning process at the university as a negative factor in reducing the health of students. In our opinion, the negative impact is manifested in part - in reducing the speed-strength qualities and increasing the frequency of breathing. Positive trends (the completion of growth processes and the adaptation process) are confirmed by the growth (by the end of the first year of training) of power qualities and indicators of the functional state.

\section{Conclusions}

1. During the first year of training, ambiguous dynamics of the functional state, speed-strength and strength qualities of students was established.

2. We suggest to consider the indicator indices of the process of female students' adaptation to learning: the results of hand dynamometry (physical development index), long jump from the place (the indicator of physical readiness), the Genci test, CEBC and the endurance factor (indicators of the functional state).

\section{Conflict of interest}

The authors state that there is no conflict of interest.

\section{References}

1. Deliens T, Deforche B, De Bourdeaudhuij I, Clarys P. Changes in weight, body composition and physical fitness after 1.5 years at university. European Journal of Clinical Nutrition, 2015; 69(12):1318-1322. doi:10.1038/ejen.2015.79

2. Ziolkowski A, Zubrzycki I, Blachnio A, Drobnik P, Zaranska $\mathrm{B}$, Moska W. Influence of sport activity on satisfaction with life and sense of coherence among physically disabled people. Baltic Journal of Health and Physical Activity. 2016;8(4):109-16.

3. Buduk-ool LK. Sociohygienic Factors For The Lifestyle In Students. Gigiena i Sanitaria, 2015; 94(5): 95-97. (in Russian)

4. Doroshenko EY, Svatyev AV, Iermakov SS, Jagiełło W. The use of cardio training facilities in training 7-9 year old judo athletes. Archives of Budo Science of Martial Arts and Extreme Sports. 2017;13.

5. Kudryavtsev M, Kramida I, Kuzmin V, Iermakov S, Cieślicka M, Stankiewicz B. Influence of study in HEE on ubiquity and strength of students' computer gambling. Physical education of students, 2016; 3: 13-22. doi:10.15561/20755279.2016.0302 23

6. Deforche B, Van Dyck D, Deliens T, De Bourdeaudhuij I. Changes in weight, physical activity, sedentary behaviour and dietary intake during the transition to higher education: a prospective study. International Journal of Behavioral Nutrition and Physical Activity, 2015; 12:16. doi:10.1186/ s12966-015-0173-9.

7. Podrigalo LV, Iermakov SS, Avdiievska OG, Rovnaya OA, Demochko HL. Special aspects of Ukrainian schoolchildren's eating behavior. Pedagogics, psychology, medical-biological problems of physical training and sports, 2017; 21(3): 120125. doi:10.15561/18189172.2017.0304

8. Buduk-ool LK, Ajzman RI. The cardiovascular system during adaptation of students residing in a South-Siberian region. Gigiena i Sanitaria, 2010; (1): 84-87. (in Russian)

9. Kuznecova DA, Sizova EN, Tuliakova OV. Features of the incidence of adolescents living in different geographical latitudes. Vestnik Ural'skoj medicinskoj akademii nauk, 2013;1:9-11. (in Russian)

10.Timofeeva AV, Klimova TM, Mikhajlova AE, Zakharova RN, Vinokurova SP, Timofeev LF. Characteristics of the somatotype and functional state of the circulatory system of student youth in the North-East of Russia. Problemy social'noj gigieny, zdravookhraneniia $i$ istorii mediciny, 2015;5:19-22. (in Russian)

11.Radziminska A, Weber-Rajek M, Lewandowska J, LulinskaKuklik E, Straczynska A, Moska W. Evaluation of the efficacy of low level laser therapy and cryotherapy in the treatment of gonarthrosis. Baltic Journal of Health and Physical Activity. 2016;8(2):87-95.

12.Castro-Piñero J, Ortega FB, Artero EG, Girela-Rejón MJ, Mora J, Sjöström M, Ruiz JR. Assessing muscular strength in youth: usefulness of standing long jump as a general index of muscular fitness. Journal of Strength and Conditioning Research, 2010; 24(7): 1810-1817. doi:10.1519/ JSC.0b013e3181ddb03d

13.Kortas J, Prusik K, Flis D, Prusik K, Ziemann E, Leaver $\mathrm{N}$, et al. Re: Possible effect of decreased insulin resistance on ferritin levels after Nordic Walking training. Clinical 
Interventions in Aging, 2016;11:150-151.

14.Pribis P, Burtnack CA, McKenzie SO, Thayer J. Trends in body fat, body mass index and physical fitness among male and female college students. Nutrients, 2010; 2(10): 10751085. doi:10.3390/nu2101075

15.Kudryavtsev M, Kramida I, Osipov A. Influence of monitor bad habits on healthy lifestyle of students. Theory and Practice of Physical Culture, 2016; 6: 24-26.

16.Osipov AY, Kudryavtsev MD, Iermakov SS, Jagiello W. Criteria for effective sports selection in judo schools - on example of sportsmanship's progress of young judo athletes in Russian Federation. Archives of Budo. 2017;13:179-186.

17.Sizova EN, Mishchenko NV, Rodygina SN, Tuliakova OV. Comparison of the physical development of 17-18-year-old girls in years 1996 and 2007 Gigiena i sanitariia, 2010;4:8688. (in Russian)

18.Fedoseev VN. An approximate program of the discipline "Physical Culture”. Novosibirsk; 2014. (in Russian)

19.Kudryavtsev MD, Kopylov YuA, Kuzmin VA, Ionova OM, Yermakova TS. Personality oriented system of strengthening of students' physical, psychic and socialmoral health. Physical education of students, 2016;3: 43-52. doi:10.15561/20755279

20.Karpenko IuD. Dynamics of the functional state and adaptation processes in students. Gigiena $i$ sanitariia, 2012;4:61-63. (in Russian)

21.Proskuriakova LA, Burnysheva TV. Assessment of morbidity, physical health of students and the formation of self-protective behavior. Problemy social'noj gigieny, zdravookhraneniia $i$ istorii mediciny, 2012;3:15-17. (in Russian)

22.Jagiełło M, Iermakov SS, Nowiński M. Differentiation of the somatic composition of students physical education specialising in various sports. Archives of Budo Science of Martial Arts and Extreme Sports. 2017;13.

23.Kriventsova I, Iermakov S, Bartik P, Nosko M, Cynarski WJ. Optimization of student-fencers' tactical training. Ido Movement for Culture-Journal of Martial Arts Anthropology. 2017;17(3):21-30. doi:10.14589/ido.17.3.3

24.Jagiello W, Kruszewski A. Morphological diversification of competitors training Greco-Roman style of wrestling. Archives of Budo. 2009;5: 147-153.

25.Korobeynikov G, Mazmanian K, Korobeynikova L, Jagiello W. Psychophysiological states and motivation in elite judokas. Archives of Budo. 2010;6(3):129-36.

26. Osipov AY, Kudryavtsev MD, Iermakov SS, Jagiello W. Topics of doctoral and postdoctoral dissertations devoted to judo in period 2000-2016-the overall analysis of works of Russian experts. Archives of Budo. 2017;13:1-10.

27.Khudolii OM, Ivashchenko OV, Iermakov SS, Rumba OG. Computer simulation of junior gymnasts' training process. Science of Gymnastics Journal. 2016;8(3):215-228.

28.Kopeikina EN, Drogomeretsky VV, Kondakov VL, Kovaleva MV, Iermakov SS. Modification of Harvard step-test for assessment of students' with health problems functional potentials. Physical Education of Students. 2016;20(4):4450. doi:10.15561/20755279.2016.0405

29.Kozina ZL, Iermakov SS, Kadutskaya LA, Sobyanin FI, Krzeminski M, Sobko IN, et al. Comparative characteristic of correlation between pulse subjective indicators of girl students' and school girls' reaction to physical load. Physical Education of Students. 2016;20(4):24-34. doi:10.15561/20755279.2016.0403

30.Podrigalo LV, Galashko MN, Iermakov SS, Rovnaya OA, Bulashev AY. Prognostication of successfulness in armwrestling on the base of morphological functional indicators' analysis. Physical Education of Students. 2017;21(1):46-51. doi:10.15561/20755279.2017.0108

31.Druz VA, Iermakov SS, Nosko MO, Shesterova LY, Novitskaya NA. The problems of students' physical training individualization. Pedagogics Psychology MedicalBiological Problems of Physical Training and Sports. 2017;21(2):51-59. doi:10.15561/18189172.2017.0201

32. Wolyniec W, Ratkowski W, Urbanski R, Bartoszewicz M, Wolyniec Z, Siluk D, et al. Urinary kim-1 but not urinary ngal is increased after short maximal exercise. Nephrology Dialysis Transplantation. 2016;31:149-149.

33.Aguado-Gomez R, Diaz-Cueto M, Hernandez-Alvarez JL, Lopez-Rodriguez A. Supporting autonomy in physical education: perception versus reality. Revista Internacional De Medicina Y Ciencias De La Actividad Fisica Y Del Deporte. 2016;16(62):183-202. doi:10.15366/rimcafd2016.62.001

34.Beni S, Fletcher T, Ni Chroinin D. Meaningful Experiences in Physical Education and Youth Sport: A Review of the Literature. Quest. 2017;69(3):291-312. doi:10.1080/003362 97.2016.1224192

35.Chen A, Wang YB. The Role of Interest in Physical Education: A Review of Research Evidence. Journal of Teaching in Physical Education. 2017;36(3):313-322. doi:10.1123/ jtpe.2017-0033

36. Hastie PA. Revisiting the National Physical Education Content Standards: What Do We Really Know About Our Achievement of the Physically Educated/Literate Person? Journal of Teaching in Physical Education. 2017;36(1):3-19. doi:10.1123/jtpe.2016-0182

37.Luz C, Rodrigues LP, Almeida G, Cordovil R. Development and validation of a model of motor competence in children and adolescents. Journal of Science and Medicine in Sport. 2016;19(7):568-572. doi:10.1016/j.jsams.2015.07.005

38.Hastie PA, Wellhead T. Models-Based Practice in Physical Education: The Case for Sport Education. Journal of Teaching in Physical Education. 2016;35(4):390-399. doi:10.1123/jtpe.2016-0092

39.Santana CCA, Azevedo LB, Cattuzzo MT, Hill JO, Andrade LP, Prado WL. Physical fitness and academic performance in youth: A systematic review. Scandinavian Journal of Medicine \& Science in Sports. 2017;27(6):579-603. doi:10.1111/sms.12773

40.Stylianou M, Enright E, Hogan A. Learning to be researchers in physical education and sport pedagogy: the perspectives of doctoral students and early career researchers. Sport Education and Society. 2017;22(1):122-139. doi:10.1080/13 573322.2016.1244665

41.Mikhajlova SV, Kuzmichev IuG, Zhulin NV. Evaluation of the functional state of students based on the results of the step test and Martine-Kushelevsky test. Vestnik Zdorov'e $i$ obrazovanie v XXI veke, 2016;12:36-38. (in Russian)

42.Podrigalo LV, Iermakov SS, Jagiello W. Special indices of body composition as a criterion of somatic development of martial arts practitioners. Archives of Budo Science of Martial Arts and Extreme Sports. 2017;13:5-12.

43.Tulyakova OV. Ecology of a man. Kirov; 2010. (in Russian)

44.Baev VM, Kudryavtseva EN. Adaptation to physical load and the state of the autonomic nervous system in young women with low blood pressure. Patologicheskaia fiziologiia i eksperimental'naia terapiia, 2015; 59(4): 97-100. (in Russian)

45.Muscle Strength Procedures Manual. National Health and Nutrition Examination Survey; 2011.

46.Pulse and Blood Pressure Procedures for Household Interviewers. National Health and Nutrition Examination 
Survey; 1993.

47.Jagiello W. Differentiation of the body build in judo competitors of the men's Polish national team. Archives of Budo. 2013;9(2):117-25.

48.Schmidt M. Predictors of self-rated health and lifestyle behaviours in Swedish university students. Global Journal of Health Science, 2012; 4(4): 1-14. doi:10.5539/gjhs.v4n4p1

49.Marakushin D, Chernobay L, Vasylieva O, Karmazina I. Intersystem integration in terms of the educational process in the initial courses of higher medical school. Georgian medical news, 2016; (256-257): 88-92.

50.Moore VC. Spirometry: step by step. Breathe, 2012; 8: 232240. doi:10.1183/20734735.0021711

51.Pullman AW, Masters RC, Zalot LC, Carde LE, Saraiva MM, Dam YY. Et al. Effect of the transition from high school to university on anthropometric and lifestyle variables in males. Applied Physiology, Nutrition, and Metabolism, 2009; 34(2): 162-171. doi:10.1139/H09-007

52.Marfell-Jones MJ, Stewart AD, de Ridder JH. International standards for anthropometric assessment. Wellington, New Zealand: International Society for the Advancement of Kinanthropometry; 2012.

53.Tulyakova OV. Functional state of the cardiovascular system and the level of physical working capacity of 7-8-year-old children in conditions of aerotechnogenic pollution. Gigiena i sanitariia, 2012;2:64-67. (in Russian)

54.Kudryavtsev MD, Kramida IE, Iermakov SS, Osipov AYu. Development dynamic of healthy life style personality component in relatively healthy students. Physical education of students, 2016; 20(6): 26-33. doi:10.15561/20755279.2016.0603

55.Bogatyrev VS. Physiological characteristics of physical development and reproductive health of graduates of secondary schools living in ecologically different territories of the Kirov region. Dokt. Diss., Moscow; 1999. (in Russian)

56.Samsonenko IV. Analysis of the health status of university students. Uchenye zapiski universiteta Lesgafta, 2015;11
(129):229-232. (in Russian)

57.Matveeva NA, Chekalova NG, Dodonov AV, Silkin IuR, Maksimenko EO. Physical development of students of higher educational institutions of Nizhny Novgorod. Medicinskij al'manakh, 2015;5(40):176-178. (in Russian)

58.Artemenkov AA. Physical development and physical fitness of students in city with bad ecological characteristics. Ekologiia cheloveka, 2012;4:39-44. (in Russian)

59.Ziatdinov AI, Mingazova EN. Development of standards for physical development of medical students on the basis of historically established traditions in the region. Sovremennye problemy nauki i obrazovaniia, 2013;6:11-15. (in Russian)

60.Deliens T, Clarys P, De Bourdeaudhuij I, Deforche B. Weight, socio-demographics, and health behaviour related correlates of academic performance in first year university students. Nutrition Journal, 2013; 12: 162-165. doi:10.1186/14752891-12-162

61.Ramírez-Vélez R, Meneses-Echavez JF, González-Ruíz K, Correa JE. Muscular fitness and cardiometabolic risk factors among Colombian young adults. Nutrición Hospitalaria, 2014; 30(4): 769-775. doi:10.3305/nh.2014.30.4.7684.

62.Deliens T, Clarys P, Van Hecke L, De Bourdeaudhuij I, Deforche $\mathrm{B}$ Changes in weight and body composition during the first semester at university. A prospective explanatory study. Appetite, 2013; 65: 111-116. doi:10.1016/j. appet.2013.01.024

63. Artero EG, España-Romero V, Castro-Piñero J, Ruiz J, Jiménez-Pavón D, Aparicio V, Gatto-Cardia M, Baena P, Vicente-Rodríguez G, Castillo MJ, Ortega FB. Criterionrelated validity of field-based muscular fitness tests in youth. Journal of Sports Medicine and Physical Fitness, 2012; 52(3): 263-272.

\section{Information about the authors:}

Avdeeva M.S.; http://orcid.org/0000-0002-6760-7347; usr11253@vyatsu.ru; Department of Physical Education, Vyatka State University; Moskovsky str., 36, Kirov, 610000, Russia

Tulyakova O.V. (Corresponding author); http://orcid.org/0000-0002-2095-4309; ov_tulyakova@vyatsu.ru; Department of Students Research Work, Vyatka State University; Moskovsky str., 36, Kirov, 610000, Russia.

Cite this article as: Avdeeva MS, Tulyakova OV. Indicated factors of physical development, physical readiness, functional condition and efficiency of female students in the process of adaptation to training. Physical education of students, 2018;22(1):411. doi:10.15561/20755279.2018.0101

The electronic version of this article is the complete one and can be found online at: http://www.sportedu.org.ua/index.php/PES/issue/archive

This is an Open Access article distributed under the terms of the Creative Commons Attribution License, which permits unrestricted use, distribution, and reproduction in any medium, provided the original work is properly cited (http://creativecommons.org/licenses/by/4.0/deed.en).

Received: 15.10 .2017

Accepted: 10.11.2017; Published: 27.02.2018 